\title{
The Role of the Jesuit University in the Evolving "Innovation Triangle" of Business, Government, and Academia
}

\author{
Robert Brancatelli ${ }^{1^{*}}$, Yeda Swirski Souza ${ }^{2}$
}

\begin{abstract}
The purpose of this paper is to suggest a role for Jesuit universities to play in the evolving collaboration among business, government, and academia. Specifically, this paper will identify an "innovation triangle" whose aim is the creation of innovative ways to meet the challenges of a global economy. For purposes of the International Association of Jesuit Business Schools 2015 Conference in Montevideo, Uruguay, the subject area is "Jesuit inspiration at the university level: business challenges."
\end{abstract}

Our methodology consists of evaluating the role of Jesuit universities through the case study of a conference organized by the presenters of this paper. Although not actually held, the conference was scheduled to take place at Unisinos Business School in São Leopoldo, Brazil. Entitled "Doing Brazil in Brazil," it involved a new structure in which participants were to work alongside government officials, university faculty, and students while exploring the ethical dimensions of foreign investment and business in Brazil. This was to have been done in conjunction with a techpark adjacent to the university.

Keywords: Jesuit universities; Jesuit inspiration; Jesuit Business Schools; innovation triangle

$21^{\text {st }}$ International Association of Jesuit Business Schools (IAJBS)

$18^{\text {th }}$ Colleagues in Jesuit Business Education (CJBE)

\section{Introduction}

In knowledge-based societies, the role of universities has been changing dramatically. Universities' historic role as knowledge centers responsible for keeping memory alive, educating youth, and proposing new ideas is giving way to more flexible ways of engaging the world. Universities now take a proactive role as a full partner with business and government in creating innovation and leveraging the economy and quality of life in cities, regions, and entire countries.

The metaphor of an "innovation triangle" is offered here as a way to express the connection among business, government, and academia. It also helps in imagining new possibilities for applying academic research to industry. Patents, technology transfer, and contracting with commercial firms have been usual practices in research universities (Etzkowitz, 2008). But recognition of the importance of an entrepreneurial mindset and attitude has spread to long-established universities as well as new ones around the globe. Programs such as the Entrepreneurial University Leaders Program (2013) in Great Britain and the Innovative and Entrepreneurial University in the United States (US Department of Commerce, 2012) attest to this trend.

In this paper, we propose a new role for Jesuit universities in the areas of innovation and entrepreneurship. In the first section we explore the concept and practices of entrepreneurial universities overall. In the second, we present what we see as the prophetic role of Jesuit universities in the innovation triangle. In the third section, we present the conference "Doing Brazil in Brazil," which is a program of executive education that gives business leaders from around the world an opportunity to work with Brazilian government officials, faculty and students. Finally, we conclude with a consideration of the opportunities and constraints present in the evolving triangle.

\section{Concept and Examples of Practices in Entrepreneurial Universities}

In the innovation triangle, business, government, and academia relate in a dynamic way to each other in order to advance economic growth through technology. This dynamism breaks down traditional organizational, cultural, and normative barriers that have separated the partners in the past and caused harm to economic competitiveness and technological progress. For the university, this new way of relating requires "an academic structure and function that is revised through the realignment of economic development with research and teaching as academic missions" (Etzkowitz et al. 2000, p. 314). This goes well beyond being a simple and logical extension of the "engaged university." The types of realignment required or implied in the triangle include: new understandings and metrics for the traditional teaching and research missions of the university; internal changes that are more conducive to interdisciplinary collaboration and collaboration with government and industry; new modes of governance and management; and new institutional capacities.

\section{Specifically, what might these new institutional capacities look like?}

- The traditional roles of faculty and student as teacher and learner interacting in a lecture hall, seminar, or laboratory would be replaced by the faculty member as a coach and students testing their knowledge in the "real world" (e.g., arranged internships).

(1) Fordham University

(2) Unisinos University

*Corresponding author: rjbrancatelli@gmail.com 
- Knowledge capitalization would become as important as knowledge production and dissemination as the measure by which faculty, departments, and institutes are evaluated. The reward and incentive structure for faculty would be changed to reflect changes in the way outputs are measured.

- The mode of production of knowledge - research - would be organized as strategic alliances and teams among a number of internal and external organizations rather than a single principal investigator directing a group of graduate students and postdocs working in a university laboratory. These alliances would be attuned to commercialization opportunities and the expectation of profit.

- The intermediary and interface functions of the university would be increased with technology transfer agents, legal specialists, contract specialists, and facilitators interacting with industry and government.

- The university would function as a seed-bed for generating and nurturing new business. It would add staff specialists experienced in new venture development for coaching and assisting faculty entrepreneurs. The culture and reward structure would inspire creativity and initiative on the part of faculty to engage in start-ups (Etzkowitz et al. 2000; Etzkowitz and Leydesdorff 2000).

\section{The Prophetic Voice of Jesuit Universities}

Several questions come to mind when considering the role of Jesuit universities in this new way. First, what has been the role of these universities historically? Second, what should be their role given their unique place in business ethics and the moral formation of students? Third, what is achievable and practical?

First, regarding the traditional role of Jesuit universities, there is a history, particularly in developing countries, of educating the families of the moneyed class. Often, these families constituted the business and political elite of society, and their interests coincided with those of established corporations, usually involving foreign investment, either directly or indirectly. While this certainly has changed over the past half century, with ample evidence from El Salvador to India, the legacy continues to influence perceptions of Jesuit education. It poses challenges in educating for the kind of servant leadership espoused by contemporary Jesuit institutions as well as efforts to promote Jesuit ideals across the university.

Second, just as many modern businesses follow a stakeholder model of governance with a triple bottom line of finance, society, and the environment, Jesuit universities have a triple bottom line of fostering the intellectual, moral, and religious development of their students as they prepare them for leadership. Often, this is expressed in such catchphrases as "educating for conscience, compassion, and competence."

These two factors--the history of Jesuit education and the Jesuit triple bottom line--present challenges and opportunities. They also continue to influence each other in subtle ways. For just as there was a bias in favor of the ruling classes in Jesuit education as late as the mid-twentieth century, there continues to be a bias toward those with influence and resources in current discussions among business, government, and academia. In other words, who is invited to the table to discuss innovation and the societal impact of investment or research is just as important as what is discussed. If the church's preferential option for the poor is reflected in Jesuit education, then a similar option ought to be considered in the evolving innovation triangle. Otherwise, a new form of elitism and marginalization will arise precisely in those areas of the world rich in resources but poor in capital.

Theologian John Haughey, who has studied universities and the role of the academy in church and society, has likened universities to "birthing rooms" in which everyone in the community must sacrifice autonomy to some extent to make room for new, "emergent" insights (Haughey, 2009, p. 15). And how is this achieved except through conscience so that the insight either emerges from or leads back to justice? For example, if a technological breakthrough now means that a pharmaceutical company can do $\mathrm{x}$, should it do $\mathrm{x}$ ? Should it do $\mathrm{x}$ in market $y$ ? The Jesuit university has an obligation at least to pose questions of conscience to balance the discussion, perhaps even to take a stand when neither business nor government is prepared to do so.

Third, the question of practicality is a valid one, although no barriers exist, either conceptually or logistically, to prevent Jesuit universities from exercising their prophetic role. Certainly, university administrators face financial constraints every day and contend with the same problems as many for-profit businesses. These include "customer" satisfaction, branding, the supply chain, employees, resource allocation, etc. Still, Jesuit universities are more than businesses, and the formative, communal, and prophetic roles they exercise are indispensable to the overall student experience.

Whether or not the exercise of this prophetic role is achievable is a function of will; that is, do Jesuit universities view themselves as prophetic, and do they want to be the voice of conscience within the innovation triangle? The answers have to do with the progress Jesuit universities have made in their own self-identity as mission-based institutions and the extent to which they are able to balance Christian humanism with the realities of diverse faculties and student bodies as well as the tremendous pressure to place graduates in the workforce.

Answers to these questions also depend upon the changing role of academia in the wider society. That is, if universities in general are to become equal partners with business and government without either duplicating what business and government do, or insisting on the primacy of theory over practice, then the way forward is to define this new role as clearly as possible. If the role is to be more or less judicial in the case of secular universities and prophetic within Jesuit universities, then this role needs to be advocated throughout the innovation triangle. The successful functioning of the partners in the triangle will depend on clear expectations.

How does all of this come together, and what are the practical outcomes for Jesuit universities? 
Based on the above, we can now propose that the role of Jesuit universities include the following

1. Identify the moral/ethical dimension of issues.

2. Conduct necessary research in technology and innovation, integrating as many segments of the university as possible (i.e., faculty and students).

3. Provide "checks and balances" to both governmental regulation on one hand and business excess on the other.

4. Offer a neutral/objective setting for dialogue and debate with as many relevant voices as possible invited to participate.

Although it might seem easy enough to point out the moral or ethical dimension of issues, advances in technology have pushed traditional understandings to new limits. Yesterday's issues like intellectual property rights and patents have given way to debates over what constitutes personhood, corporate citizenship, access to natural resources, privacy, and even consciousness itself. Identifying the moral or ethical dimension of these issues and their salient points may not be as easy as it seems. Secondly, involving different stakeholders and communities in the discussion of research and funding speaks to the essence of what it means to be a Jesuit institution concerned with "other." Third, because of their perceived impartiality and fairness, Jesuit universities may be able to challenge the over-regulation of industries by government and excessive development by multinational corporations. Finally, Jesuit universities can provide a forum for the exploration of new ideas and the resolution of conflict within the innovation triangle. There is perhaps no other institution with the requisite credibility and trust.

We believe that these four functions will enable Jesuit universities to play a decisive role in decisions ranging from research and investment to product development. Perhaps even more importantly, they represent specific ways in which a Jesuit university can model how a deeply-held concern for other can effect change beyond the ivy walls of academia.

\section{"Doing Brazil in Brazil"}

We have considered the entrepreneurial and prophetic dimensions of Jesuit universities in a conceptual way. But what, exactly, do these dimensions look like in practice? Moreover, where does a Jesuit university begin? Does this re-emphasis in identity require a special task force or the intentional formation of faculty and staff? These are valid concerns, although what follows is not a blueprint for implementing the new model but a way in which the culture of the university might begin to change. We believe that once people imagine the role of the university in new ways, the specifics of formation, training, and programming will develop from there. This is especially true given the varied size, scope, and location of Jesuit universities around the world, each with its unique social, cultural, political, and ecclesial contexts. And it is certainly true of their business schools.

"Doing Brazil in Brazil" will take place at a time to be determined at Unisinos University and the Tecnosinos Technology Park, both in São Leopoldo, Brazil. It is designed for executives interested in either establishing or strengthening their presence in Brazil by examining the larger cultural environment and how that environment influences innovation, technology, and investment. It will emphasize two major areas: (1) the complexity of Brazil, which consists of different cultures, ethnic groups, languages, and history, and (2) what we call the "ethical imperative," which asks businesses to understand that complexity, to work within it, and to create products and services that derive from and lead back not just to Brazilian markets but to Brazilian society. By honoring markets and people in this way, we believe that corporations will have a much better chance not merely to survive in Brazil but to thrive there.

Unisinos is partnering with Fordham University and Fordham Road Collaborative, a private consulting firm, both in New York City. All three sponsors are steeped in Jesuit mission and education, and so working on the ethical imperative will be easier than if there were a mix of secular, state, and other private institutions. This is an advantage, at least in the early stages of development, although it is hoped that the model eventually is followed by other Jesuit universities and then beyond. Business sponsors include General Electric and SAP.

Doing Brazil in Brazil" will last four days and include information sharing sessions, panels, municipal tours, on-site visits to companies, and team projects. From the first day, however, the focus will be on solving actual problems in innovation and technology as identified at Tecnosinos. Participants will work with members of local industry, university faculty, and select students to produce real solutions that will be presented to government representatives, who will also work with the teams.

This kind of hands-on engagement in real projects meets the needs of business leaders while challenging them to move beyond the utilitarian thinking of "what works." As stated earlier, the ethical dimension of team projects will be explored with emphasis on the four points listed in the previous section. It is hoped that the teams will come to view ethics not as an a posteriori embellishment but a constitutive part of decision-making. In addition, they will leave the conference prepared to deal with issues of corruption, which continues to be a problem in both business and government in Brazil.

Finally, one of the characteristics that makes "Doing Brazil in Brazil" unique is the inclusion of students. Helping students develop their intercultural and global leadership skills has been an important part of Jesuit business education. But the benefits do not flow in one direction only. The involvement of students can help the other participants, since youth culture is as distinct in Brazil as it is in any other region of the globe. Thus, we hope that "Doing Brazil in Brazil" will inspire future conferences in which students from Jesuit universities in developed countries can work in the same collaborative manner on real problems in developing countries.

\section{Final Considerations}

We have proposed a new role for Jesuit universities in the "innovation triangle" of business, government, and academia. This role 
includes entrepreneurship and innovation. It also includes prophecy in the biblical sense of calling the community (i.e., the triangle) to right relationships among themselves and with the rest of society. We have also presented a model for how this role might be played in a practical way. The model is "Doing Brazil in Brazil," a conference that does two important things: (1) invites business executives, government officials, faculty, and students to work together on common problems that affect real markets, and (2) defines an "ethical imperative" for Jesuit partners in the triangle to follow so that the voice of conscience is heard.

Regarding the prophetic dimension of this new role of Jesuit universities, we have identified four tasks that can guide the development of more specific programming. As stated above, these include: (1) to identify the ethical dimension of issues, (2) to conduct necessary research with faculty and students, (3) to provide "checks and balances" to governmental regulation and business interests, and (4) to offer a neutral setting for debate. These four represent a starting point, and we have no doubt that they will be refined through practice and time.

We are also cognizant of the many obstacles to accepting this new model and following it in an effective way. Not the least of these is convincing an already overworked faculty and administration not just to try something different, but to envision new ways of teaching, learning, and sustaining academic communities. The good news is that this is not the first (or last) attempt to align mission with profitability in a Jesuit educational setting. Making gradual changes and inviting all stakeholders to the table will help tremendously. The possibility of developing student skills in global leadership through a conference like "Doing Brazil in Brazil" is, of course, another benefit.

Other constraints are familiar and have become an accepted part of what it means to be a Jesuit institution of higher education in the twenty-first century. These include the historical association of Jesuit education with the elite, particularly in developing countries; bias against working with a religious institution; and the tendency to favor privileged classes in the new triangle. There is also the challenge for the partners in the triangle to move beyond think-tank status to action.
Finally, if in the past Jesuit universities provided the brain-power to create competitive advantage for business and cutting-edge technology for government, it is time for them to assert themselves as centers of innovation sui generis and not merely as purveyors of goods and services to clients, whether industrial or state-sponsored. This may involve challenging the underlying logic behind decisions in public policy and organizational governance. It means that Jesuit universities, in particular, have an opportunity not merely to play devil's advocate but to do the one thing that neither business nor government has been able to do: act as the conscience of the innovative triangle. Jesuit universities are uniquely, and perhaps solely, positioned to do so.

\section{Acknowledgements}

The authors would like to thank Unisinos University for their kind support and sponsorship of "Doing Brazil in Brazil."

\section{References}

Centre, T.N. (2013, December). The entrepreneurial university: from concept to action. The National Centre for Entrepreneurship in Education.

Etzkowitz H, Leydesdorff L (2000). The dynamics of innovation: from national systems and "Mode 2" to a triple helix of university-industry-government relations. Research Policy 29, 109-123.

Etzkowitz H,Webster AC, Terra, BRC (2000). The future of the university and the university of the future: evolution of ivory tower to entrepreneurial paradigm. Research Policy 29, 313-330.

Haughey, John. (2009). Where is knowing going? The horizons of the knowing subject. Washington, DC: Georgetown University Press.

The Innovative and Entrepreneurial University. (2013). United States Department of Commerce. http://www.eda.gov/pdf/The_Innovative_and_Entrepreneurial_University_Report.pdf. 